\title{
Sexual dimorphism and allometry in the sphecophilous rove beetle Triacrus dilatus
}

Maxwell H Marlowe, Cheryl A Murphy, Stylianos Chatzimanolis

The rove beetle Triacrus dilatus is found in the Atlantic forest of South America and lives in the refuse piles of the paper wasp Agelaia vicina. Adults of $T$. dilatus are among the largest rove beetles, frequently measuring over $3 \mathrm{~cm}$, and exhibit remarkable variation in body size. To examine sexual dimorphism and allometric relationships we measured the length of the left mandible, ocular distance and elytra. We were interested in determining if there are quantifiable differences between sexes, if there are major and minor forms within each sex and if males exhibit mandibular allometry. For all variables, a t-test was run to determine if there were significant differences between the sexes. Linear regressions were run to examine if there were significant relationships between the different measurements. A heterogeneity of slopes test was used to determine if there were significant differences between males and females. Our results indicated that males had significantly larger mandibles and ocular distances than females, but the overall body length was not significantly different between the sexes. Unlike most insects, both sexes showed positive linear allometric relationships for mandible length and head size (as measured by the ocular distance). We found no evidence of major and minor forms in either sex. 
1 Sexual dimorphism and allometry in the sphecophilous rove beetle Triacrus

2 dilatus.

3

\section{Abstract}

The rove beetle Triacrus dilatus is found in the Atlantic forest of South America and lives in the refuse piles of the paper wasp Agelaia vicina. Adults of $T$. dilatus are among the largest rove beetles, frequently measuring over $3 \mathrm{~cm}$, and exhibit remarkable variation in body size. To examine sexual dimorphism and allometric relationships we measured the length of the left mandible, ocular distance and elytra. We were interested in determining if there are quantifiable differences between sexes, if there are major and minor forms within each sex and if males exhibit mandibular allometry. For all variables, a t-test was run to determine if there were significant differences between the sexes. Linear regressions were run to examine if there were significant relationships between the different measurements. A heterogeneity of slopes test was used to determine if there were significant differences between males and females. Our results indicated that males had significantly larger mandibles and ocular distances than females, but the overall body length was not significantly different between the sexes. Unlike most insects, both sexes showed positive linear allometric relationships for mandible length and head size (as measured by the ocular distance). We found no evidence of major and minor forms in either sex.

Corresponding author: Stylianos Chatzimanolis, Department of Biological and Environmental Sciences, University of Tennessee at Chattanooga, 615 McCallie Ave. Dept. 2653, Chattanooga, TN 37403, USA, +14234254236, stylianos-chatzimanolis@utc.edu 


\section{Introduction}

The order Coleoptera, or beetles, is one of the most speciose lineages of all animals with more than 400,000 species described (Hammond, 1992). Static allometry (regression analysis of the size of a structure against body size; Eberhard, 2009) has been studied extensively in beetles, due to the presence of exaggerated morphologies (sensu Emlen \& Nijhout, 2000) in many taxa. These studies first became popular in the families Scarabaeidae and Lucanidae where head and/or thoracic horns and mandibles, respectively, are frequently exaggerated (for reviews of earlier studies and other families see Eberhard \& Gutiérrez, 1991; Emlen \& Nijhout, 2000; Emlen, Hunt \& Simmons, 2005; Miller \& Wheeler, 2005; Kawano, 2006). In recent years, static allometry studies have included many other beetle families, including Anthribidae (prothorax length; Mattos, Mermudes \& Moura, 2014), Cantharidae (male genitalia; Bernstein \& Bernstein, 2002), Dytiscidae (body size; Fairn, Alarie \& Schulte-Hostedde, 2007a), Gyrinidae (body size; Fairn, Alarie \& Schulte-Hostedde, 2007b), and Leiodidae (mandibular horns; Miller \& Wheeler, 2005).

The rove beetles (Coleoptera: Staphylinidae) are a hyperdiverse family with more than 60,000 species described (unpublished database maintained by A. Newton). Triacrus dilatus Nordmann belongs in the subtribe Xanthopygina, a monophyletic lineage of 29 neotropical genera, that includes some of the largest and most colorful of all rove beetles. While little is known about the behavior and natural history of xanthopygine beetles (Chatzimanolis 2003, 2014a), T. dilatus appears to have a fascinating natural history, occupying the nest refuse piles of the large paper wasp Agelaia vicina (de Saussure) in the Atlantic forests of Brazil, Argentina and Paraguay (Wasmann, 1902; Kistner, 1982). Adults and larvae of $T$. dilatus were seen feeding on fly larvae and breeding on the refuse piles of the paper wasp (Wasmann, 1902). While many details on the natural history of $T$. dilatus are still lacking, it is possible that $T$. dilatus exhibits the same behavior as Quedius (Velleius) dilatatus (Fabricius), a central European species also associated with paper wasps (Kistner, 1982). Both Q. dilatatus and T. dilatus have subserrate (asymmetrical, looking like marginal teeth-like structures pointing forward) antennae (visible on Fig. 3), which is often characteristic of rove beetles associated with social Hymenoptera (Schillhammer, 2013; Chatzimanolis, 2014b; Zhao \& Zhou, 2015). According to zur Strassen (1957), Q. dilatatus is able to locate the paper wasps nests by following specific semiochemicals emitted by the wasps, and it is likely that $T$. dilatus can do the same.

While completing a taxonomic review of the species (Chatzimanolis, in press), one of the authors (SC) was surprised with the sheer variation in mandible length, head size and overall body length among different specimens of $T$. dilatus, both among males and females. While sexual dimorphism is common in xanthopygine rove beetles (e.g., Chatzimanolis, 2004, 2012), intraspecific variation is typically not present. In this paper we are interested in examining the sexual dimorphism and allometry in T. dilatus by measuring and analyzing the relationships between mandible length, ocular distance (head size) and elytra length (as a surrogate for body 
90

length) in both males and females. Since variation in mandible length has been associated with differential reproductive strategies in rove beetles (Forsyth \& Alcock, 1990; Hanley, 2001), we are interested in asking if males exhibit mandibular allometry. Additionally, variation in body length or head size is sometimes indicative of major and minor individuals (Emlen \& Nijhout, 2000) so we want to test whether there is quantifiable sexual size dimorphism in T. dilatus and whether there is dimorphism (major and minor individuals) within each sex.

\section{Materials and Methods}

\section{Specimens}

Specimens of $T$. dilatus are rather rare in museum collections, despite their relative large length (22-36mm). We were able to borrow specimens from the following Natural History Museums, and even though this list in not exhaustive, it includes most specimens of Triacrus ever collected (Chatzimanolis, in press; numbers next to the acronym indicate how many specimens were used from each museum): Natural History Museum, London (BMNH, 13), Field Museum (FMNH, 15), Museum of Comparative Zoology (MCZ, 1), Naturhistorisches Museum Wien (MNW, 17), Finnish Museum of Natural History $(\mathrm{MZH}, 3)$ and the University of Tennessee at Chattanooga Insect Collection (UTCI, 2). Due to the specialized habitat of these beetles and their rarity, it was impossible to have specimens only from a single locality to control for geographic variation. To reduce any geographic bias we included all specimens that we were able to examine, including both sexes. Photographs (Fig. 1) were taken using a Visionary Digital Passport system with a Canon EOS 40D camera and Canon 50mm and MP-E 65mm macro lenses. We took photographs in multiple focal plains and then these images were automontaged using Helicon Focus 6.2.2 (http://www.heliconsoft.com/heliconsoft-products/helicon-focus/) to produce a single fully focused image. To establish a method of reliably referring to particular specimens, all specimens lacking unique identification numbers were given a UTCI barcode with a human readable number sequence. These barcodes do not establish ownership of specimens and they are simply used to associate particular measurements with a specimen.

\section{Measurements}

Measurements were taken using an ocular micrometer on an Olympus ZX61 stereomicroscope. Measurements were first recorded as units of the ocular micrometer scale and were converted later into mm. All measurements, as well as the label information for all specimens, are available in Supplemental Table S1. We measured the length of the left mandible, the ocular distance (i.e. distance between the eyes) and the length of the elytra. In all cases, measurements (Fig. 1) were made between two clear reference points and beetles were positioned carefully to avoid any bias in measuring and to achieve the same plane of view. The left mandible length was measured from 
the tip of the mandible to the base of the mandible (mandibular condyle) and this was used as an indication of overall mandibular length. Both left and right mandibles are equal in size. The ocular distance was measured in a straight line between the two eyes. This measure was used as a proxy for the overall head width since the concavity of the lateral borders of head makes it hard to establish other precise points for measurements. The elytra length was measured from the tip of the mesoscutellum to the posterior border of the elytra. We used that measure as an indication of overall body length because rove beetles tend to have telescopic abdomens making it impractical to measure overall body length.

\section{Data Analyses}

All analyses were performed in SPSS 21 (Armonk, NY: IBM Corp). Data were tested for normality and homogeneity of variances using the Shapiro-Wilk test and Levene's test for equality of variance, respectively. Frequency distributions for each sex and variable were made to visually confirm these unimodal distributions (Supplemental Figs. S1-6).

For each variable measured (left mandible, ocular distance and elytra length), a 2-tailed t-test was conducted to determine if there were significant differences between males and females. Linear regressions and heterogeneity of slopes tests were performed for the following relationships: elytra length and ocular distance, elytra length and left mandible, and ocular distance and left mandible. This allowed us to further examine any differences between males and females by testing for differences in allometry.

In order to determine if there was dimorphism within each sex for each of the measurements, a test for non-linearity was performed by fitting the data to the equation:

$$
\ln Y=\alpha_{0}+\alpha_{1} \ln X+\alpha_{2} \ln X^{2}+\varepsilon
$$

where $\ln Y$ and $\ln X$ are the natural logarithms of the variables of interest; $\alpha_{\mathrm{i}}$ are the regression coefficients; and $\varepsilon$ is the random component (after Eberhard \& Gutiérrez, 1991; Hanley, 2001; Kotiaho \& Tomkins, 2001). If the coefficient $\alpha_{2}$ was not significantly different from zero, the relationship was assumed to be linear and therefore, there was no evidence of dimorphism for that particular sex/trait.

\section{Results}

T-test analyses indicated that males had significantly larger left mandibles and ocular distances than females (Left Mandible: $\mathrm{t}_{49}=-2.65, \mathrm{p}=0.011$; Ocular Distance: $\mathrm{t}_{49}=-2.51, \mathrm{p}=0.015$; Fig. 
2). However, the elytra lengths of males and females were not significantly different from each other $\left(\mathrm{t}_{49}=-1.62, \mathrm{p}=0.113\right.$; Fig. 3$)$.

Linear regression analyses showed that every relationship was significant and positive (Table 1, Figs. 3-5). When comparing the linear regressions between males and females for elytra length vs. left mandible, we found that both the slopes and intercepts for the relationships were not significantly different from one another (Table 2, Fig. 3). The same was found when comparing males and females for ocular distance vs. left mandible; there were no significant differences between the two (Table 2, Fig. 4). However, when examining elytra length vs. ocular distance, males had a significantly larger slope than the females (intercepts were not significantly different) (Table 2, Fig. 5). This indicates that for equal increases in elytra length (or body length), males would have a larger increase in ocular distance than females.

To determine if there was dimorphism within each sex (major and minor forms), we tested for non-linearity. We found that for every relationship, for both males and females, $\alpha_{2}$ was not significantly different from zero (Table 3, Figs. 3-5). Therefore, each relationship was linear in nature and there was no indication of dimorphism within each sex for any of the relationships. Because we did not find dimorphism within each sex, no further analyses were performed to determine a switch point for the variable of interest. Because the data had a normal distribution, equal variances and linear relationships (Supplemental Table S2-S3), data are shown without any transformations (i.e. natural log transformation).

\section{Discussion}

Our results showed that there are significant differences in mandibular length and head size (ocular distance) between males and females, with males having larger mandibles and heads. It is possible that mandible size is not entirely independent from the size of the head, because larger mandibles will probably require more room for the muscles associated with them. There are no behavioral data on how male (or female) T. dilatus use their mandibles besides capturing food. It is unlikely that they use them to interact with the paper wasps $A$. vicina, whose nest refuse piles they are occupying, because $A$. vicina is a well-studied organism (e.g., Zucchi et al., 1995; Sakagami et al., 1996; Baio et al., 1998; Mancini et al., 2006; Oliveira, Noll \& Wenzel, 2010; Moretti et al., 2011; Souza et al., 2013) and there are no reported interactions.

Despite the sheer diversity of rove beetles, there have been just a handful of studies in this group dealing with sexual dimorphism using a statistical approach (Forsyth \& Alcock, 1990; Thayer, 1992; Hanley, 2001). Thayer (1992) showed that there was sexual wing dimorphism in Omalium flavidum Hamilton, while the other two studies examined mandibular allometry in males of Leistrotrophus versicolor (Gravenhorst) (Forsyth \& Alcock, 1990) or in the genus Oxyporus (Hanley, 2001). Both the L. versicolor and the Oxyporus studies revealed the presence of major 
and minor males (as evident by mandibular allometry), something that we did not detect in $T$. dilatus. Both of these studies (Forsyth \& Alcock, 1990; Hanley, 2001) attributed the presence of major and minor males to different reproductive strategies among males living in ephemeral habitats (vertebrate dung for L. versicolor and fungi for Oxyporus). On the other hand, the habitat of T. dilatus, appears to be less ephemeral with the nests of Agelaia vicina being the largest of all wasps and bees (Zucchi et al., 1995) and lasting for more than six months (De Oliveira, Noll \& Wenzel, 2010). While we do not have any direct observations of T. dilatus, based on the mandibular analyses results alone, it appears that males of T. dilatus do not operate in a similar fashion as L. versicolor and Oxyporus. Perhaps $T$. dilatus do not have male differential reproductive strategies (at least with respect to morphology), although they could be using their mandibles for competition and resource allocation.

The majority of insect allometric studies have identified exaggerated morphologies in males (review by Emlen \& Nijhout, 2000; Bernstein \& Bernstein, 2002; Emlen, Hunt \& Simmons, 2005; Tomkins, Katiaho \& LeBas, 2005; Mattos, Mermudes \& Moura, 2014). Examples of positive static allometry in females are not common in the literature (but see Kelly, 2014). However, our results indicate a positive allometric relationship regarding mandibular size and ocular distance in both males and females. In fact, all slopes were larger than 1.0 and linear for every relationship examined (for both sexes) without significant differences between the sexes. The only significant difference between the sexes was that males would have a higher increase in head size for equal increase in body length. That result could imply that males tend to allocate more resources in building a larger head, perhaps for male-male competition, but we have no empirical evidence to support this claim. In addition, despite the presence of large and small individuals, we found no statistical evidence for dimorphism within each sex since our slopes were linear and not sigmoid or completely broken as expected in taxa with major and minor individuals (Emlen \& Nijhout, 2000; Hanley, 2001).

Teder and Tammaro (2005) indicated that in $80 \%$ of all examined insect species the females were the larger sex. In our study, while there is a trend for larger males than females (as measured by elytra length), there is no significant sexual size dimorphism in T. dilatus. Teder and Tammaru (2005) and Kawano (2006) found out that the mean body length was larger in sexually dimorphic species. However, it appears that xanthopygine rove beetles (where T. dilatus belongs) do not follow this pattern. Examination of the largest (in terms of length) genera in the subtribe (Triacrus Nordmann, Trigonopselaphus Gemminger and Harold, Terataki Chatzimanolis and Elmas Blackwelder) showed that while there is sexual dimorphism in all these genera, there were no significance differences in size between males and females (this study; Chatzimanolis, unpublished data). Further examination of all genera in the subtribe Xanthopygina revealed that while sexual dimorphisms are common, there were no significance differences in size between males and females (Chatzimanolis, unpublished data). Due to the lack of data regarding this hyperdiverse family, it is unclear if this is a general trend in rove beetles or if xanthopygines are the exception. 
Even though sexual size dimorphism is not widespread in xanthopygine rove beetles, sexual dimorphism (or presence of secondary sexual traits) is common in many different genera. In xanthopygine rove beetles, males have modified abdominal genital sternites (e.g., Ashe \& Chatzimanolis, 2003; Chatzimanolis, 2004, 2008, 2015), presence of a glandular porose structure on abdominal sternite VII (Chatzimanolis 2013, 2015) or modified antennae (Chatzimanolis 2012), features that are all missing or not modified in females. Chatzimanolis (2005) examined in a phylogenetic context the evolution of secondary sexual structures, and specifically the modification on abdominal sternite VIII (the last abdominal ventral segment before the genital segment), among different species of Nordus Blackwelder. He found that while there was no variation within species, the same structure seemed to have changed multiple times among different species. While Triacrus is a monotypic genus and we cannot compare variation among different species, it is remarkable to report such variation within species. The results reported here for the genus Triacrus are at odds with the pattern observed in Nordus (no intraspecific variation) and other Xanthopygina genera (e,g,, Plociopterus Kraatz; Chatzimanolis pers. observ.), It is possible, however, that the lack of variation within species for the genera Nordus and Plociopterus is due to insufficient observations and not a true pattern.

\section{Conclusions}

Our analyses documented positive mandibular and ocular distance allometry in both males and females. We also uncovered significant differences between males and females regarding mandibular length and ocular distance (head size). While males had larger mandibles and head, the average body length between males and females was not significantly different; therefore no significant sexual size dimorphism was detected. All allometric relationships were linear and we were unable to find discrete major or minor individuals in either sex.

273

274

275

276

277

278

279

280

281

282

283

\section{Acknowledgements}

We thank the curators and collections managers of the collections listed in the Materials and Methods section for the loan of specimens. Lu Musetti and Jim Carpenter helped us clarify the correct name of the paper wasp.

\section{References}


Ashe J, Chatzimanolis S. 2003. A revision of the genus Elmas Blackwelder, 1952 (Coleoptera: Staphylinidae), with a preliminary reconstructed phylogeny of the species. Scientific Papers of the Natural History Museum of the University of Kansas 28: 1-41.

Baio MV, Noll FB, Zucchi R, Simões D. 1998. Non-allometric caste differences in Agelaia vicina (Hymenoptera, Vespidae, Epiponini). Sociobiology 34: 465-476.

Bernstein S, Bernstein R. 2002. Allometry of male genitalia in a species of soldier beetle: support for the one-size-fits-all hypothesis. Evolution: 1707-1710.

Chatzimanolis S. 2003. Natural history and behavior of Nordus fungicola (Coleoptera: Staphylinidae). Annals of the Entomological Society of America 96: 225-230.

Chatzimanolis S. 2004. A revision of the neotropical genus Nordus Blackwelder (Coleoptera: Staphylinidae: Xanthopygina). Entomologische Abhandlungen 62: 3-64.

Chatzimanolis S. 2005. Phylogeny of the neotropical rove beetle genus Nordus (Coleoptera: Staphylinidae) with a special reference to the evolution of coloration and secondary sexual characters. Systematic Entomology 30: 267-280.

Chatzimanolis S. 2008. A revision of the neotropical beetle genus Isanopus Sharp, 1876 (Coleoptera: Staphylinidae: Staphylinini). Journal of Natural History 42: 1765-1792. DOI: $10.1080 / 00222930802124057$

Chatzimanolis S. 2012. Zackfalinus, A new genus of Xanthopygina (Coleoptera: Staphylinidae: Staphylinini) with description of 20 new species. Annals of Carnegie Museum 80: 261-308. DOI: $10.2992 / 007.080 .0401$

Chatzimanolis S. 2013. Terataki, a new genus of Staphylinini (Coleoptera: Staphylinidae: Staphylininae) from South America. Zootaxa 3750 (3): 251-264. DOI: 10.11646/zootaxa.3750.3.5

Chatzimanolis S. 2014a. Phylogeny of xanthopygine rove beetles based on six molecular loci. Systematic Entomology 39: 141-149. DOI: 10.1111/syen. 12040

Chatzimanolis S. 2014b. Darwin's legacy to rove beetles (Coleoptera, Staphylinidae): A new genus and a new species, including materials collected on the Beagle's voyage. ZooKeys 379: 29-41. DOI: 10.3897/zookeys.379.6624

Chatzimanolis S. 2015. A review of the genus Scaponopselaphus Scheerpeltz (Insecta: Coleoptera: Staphylinidae). Biodiversity Data Journal 3: e4735. DOI: 10.3897/BDJ.3.e4735 
325

326

327

328

329

330

331

332

333

334

335

336

337

338

339

340

341

342

343

344

345

346

347

348

349

350

351

352

353

354

355

356

357

358

359

360

361

362

363

Chatzimanolis S. In press. New records, redescription and notes on nomenclature for Triacrus Nordmann (Staphylinidae: Staphylininae: Staphylinini). The Coleopterists Bulletin.

De Oliveira OAL, Noll FB, Wenzel JW. 2010. Foraging behavior and colony cycle of Agelaia vicina (Hymenoptera: Vespidae; Epiponini). Journal of Hymenoptera Research 19: 4-11.

Eberhard WG, Gutiérrez EE. 1991. Male dimorphism in beetles and earwigs and the question of developmental constraints. Evolution 45: 18-28.

Eberhard WG. 2009. Static allometry and animal genitalia. Evolution 63: 48-66.

Emlen DJ, Nijhout HF. 2000. The development and evolution of exaggerated morphologies in insects. Annual Review of Entomology 45: 661-708.

Emlen DJ, Hunt J, Simmons LW. 2005. Evolution of sexual dimorphism and male dimorphism in the expression of beetle horns: phylogenetic evidence for modularity, evolutionary lability, and constraint. The American Naturalist 166: S42-S68.

Fairn E, Alarie Y, Schulte-Hostedde A. 2007a. Sexual size dimorphism in the diving beetle Laccophilus maculosus Say (Coleoptera: Dytiscidae). The Coleopterists Bulletin 61: 409-418.

Fairn E, Alarie Y, Schulte-Hostedde A. 2007b. Sexual size and shape dimorphism in Dineutus nigrior (Coleoptera: Gyrinidae). The Coleopterists Bulletin 61: 113-120.

Forsyth A, Alcock J. 1990. Female mimicry and resource defense polygyny by males of a tropical rove beetle, Leistotrophus versicolor (Coleoptera: Staphylinidae). Behavioral Ecology and Sociobiology 26: 325-330.

Hammond PM. 1992. Species Inventory. In: Groombridge B, ed. Global biodiversity, status of the Earth's living resources. London: Chapman \& Hall, 17-39.

Hanley RS. 2001. Mandibular allometry and male dimorphism in a group of obligately mycophagous beetles (Insecta: Coleoptera: Staphylinidae: Oxyporinae). Biological Journal of the Linnean Society 72: 451-459.

Kawano K. 2006. Sexual dimorphism and the making of oversized male characters in beetles (Coleoptera). Annals of the Entomological Society of America 99: 327-341. 
364 Kelly CD. 2014. Sexual selection, phenotypic variation, and allometry in genitalic and nongenitalic traits in the sexually size-dimorphic stick insect Micrarchus hystriculeus. Biological Journal of the Linnean Society 113: 471-484.

Kistner DH. 1982. The social insects' bestiary. In: Hermann HR, ed. Social Insects, Volume III. New York: Academic Press, 1-244.

Kotiaho JS, Tomkins JL. 2001. The discrimination of alternative male morphologies. Behavioral Ecology 12: 553-557.

Mancini K, Lino-Neto J, Campos LAO, Dolder H. 2006. Sperm ultrastructure of the wasp Agelaia vicina (Hymenoptera, Vespidae). Insectes Sociaux 53: 333-338.

Mattos I, Mermudes JRM, Moura MO. 2014. Dimorphism and allometry of Systaltocerus platyrhinus and Hypselotropis prasinata (Coleoptera: Anthribidae). Zoologia 31: 51-62.

Miller KB, Wheeler QD. 2005. Asymmetrical male mandibular horns and mating behavior in Agathidium Panzer (Coleoptera: Leiodidae). Journal of Natural History 39: 779-792.

Moretti T de C, Giannotti E, Thyssen PJ, Solis DR, Godoy WA. 2011. Bait and habitat preferences, and temporal variability of social wasps (Hymenoptera: Vespidae) attracted to vertebrate carrion. Journal of Medical Entomology 48: 1069-1075. DOI: 10.1603/ME11068

Sakagami SF, Zucchi R, Yamane SO, Noll FB, Camargo JMP. 1996. Morphological caste differences in Agelaia vicina, the Neotropical swarm-founding polistine wasp with the largest colony size among social wasps (Hymenoptera: Vespidae). Sociobiology 28: 207-23

Schillhammer H. 2013. Revision of the Asian species of Taxiplagus Bernhauer and Pseudomoeocerus Cameron. Koleopterologische Rundschau 83: 97-126.

Souza GK, Pikart TG, Jacques GC, Castro AA, Souza MM de, Serrão JE, Zanuncio JC. 2013. Social wasps on Eugenia uniflora Linnaeus (Myrtaceae) plants in an urban area. Sociobiology 60: 204-209. DOI: 10.13102/sociobiology.v60i2.204-209

Strassen R zur. 1957. Zur Ökologie des Velleius dilatatus Fabricius, eines als Raumgast bei Vespa crabro Linnaeus lebenden Staphylinidae (Ins. Col.). Zeitschrift für Morphologie und Ökologie der Tiere 46: 244-292.

Teder T, Tammaru T. 2005. Sexual size dimorphism within species increases with body size in insects. Oikos 108: 321-334. 
405 Thayer MK. 1992. Discovery of sexual wing dimorphism in Staphylinidae (Coleoptera):

406 "Omalium" flavidum, and a discussion of wing dimorphism in insects. Journal of the New York

407 Entomological Society 100: 540-573.

408

409 Tomkins JL, Kotiaho, JS, LeBas NR. 2005. Matters of scale: positive allometry and the

410 evolution of male dimorphisms. The American Naturalist 165: 389-402.

411

412 Wasmann E. 1902. Riesige Kurzflügler als Hymenopteren-Gäste. (132 Beitrag zur Kenntniss der

413 Myrmekiphilen und Termitophilen). Insektenborse 19: 267-268, 275-276, 282.

414

415

416

417

418

419

420

421

422

423

424

425

426

427

428

429

430

431

Zhao Z-Y, Zhou H-Z. 2015. Phylogeny and taxonomic revision of the subgenus Velleius Leach (Coleoptera: Staphylinidae: Staphylininae). Zootaxa 3957: 251-276. DOI:

10.11646/zootaxa.3957.3.1

Zucchi R, Sakagami SF, Noll FB, Mechi MR, Mateus S, Baio MV, Shima SN. 1995. Agelaia vicina, a swarm-founding Polistine with the largest colony size among wasps and bees (Hymenoptera: Vespidae). Journal of the New York Entomological Society 103: 129-137. 
1

Dorsal view of $T$. dilatus with measurements

Fig. 1. Dorsal view of Triacrus dilatus showing the measurement of left mandible (A), ocular distance (B) and elytra length (C). 
PeerJ Reviewing Manuscript

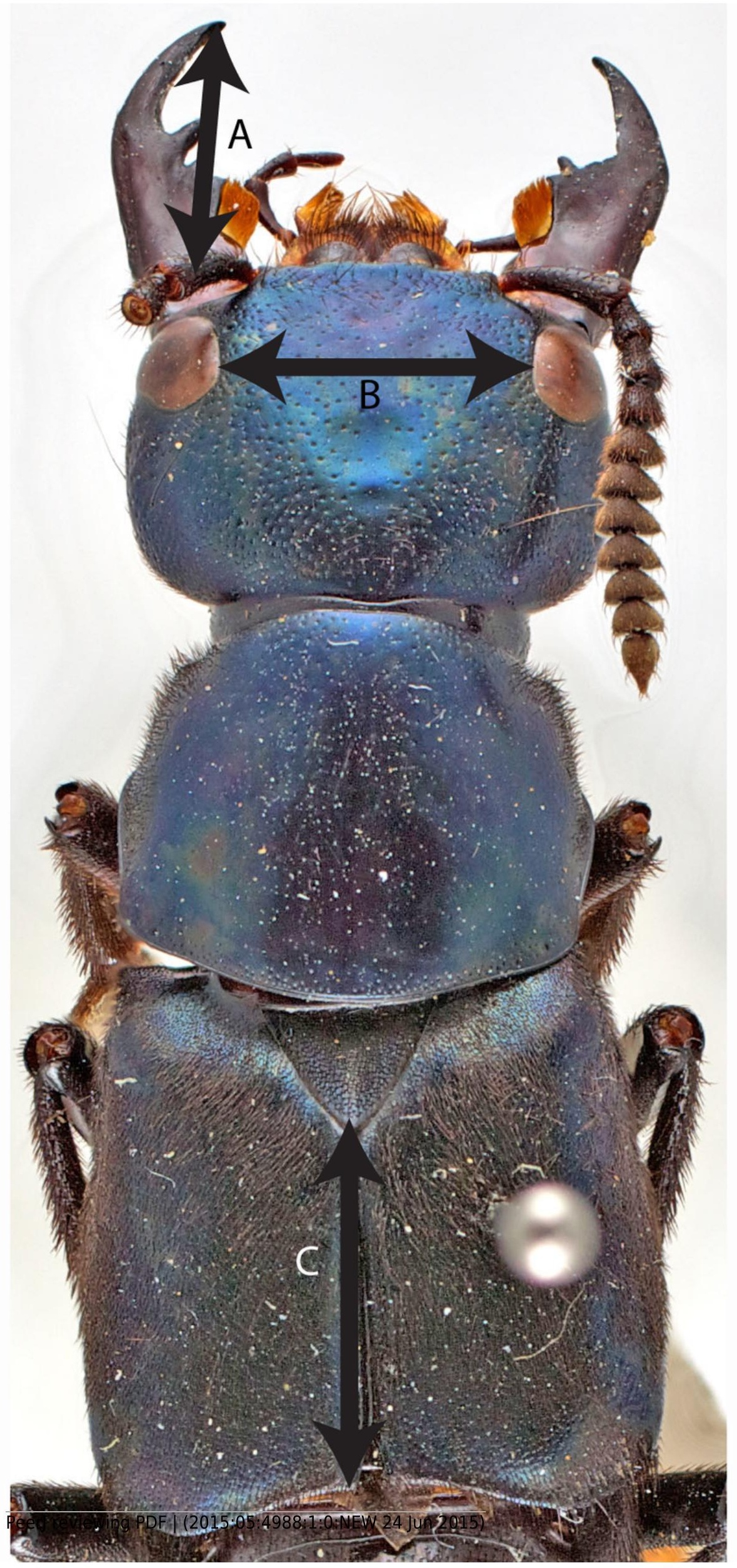


2

Means and SD of left mandible, ocular distance and elytra length

Fig 2 Means and SD of left mandible, ocular distance and elytra length, both male and female. Two-tailed T-tests were performed to determine significant differences between male and female for each variable: $\mathrm{ns}=$ no significant difference; $* \mathrm{p}<0.05$.

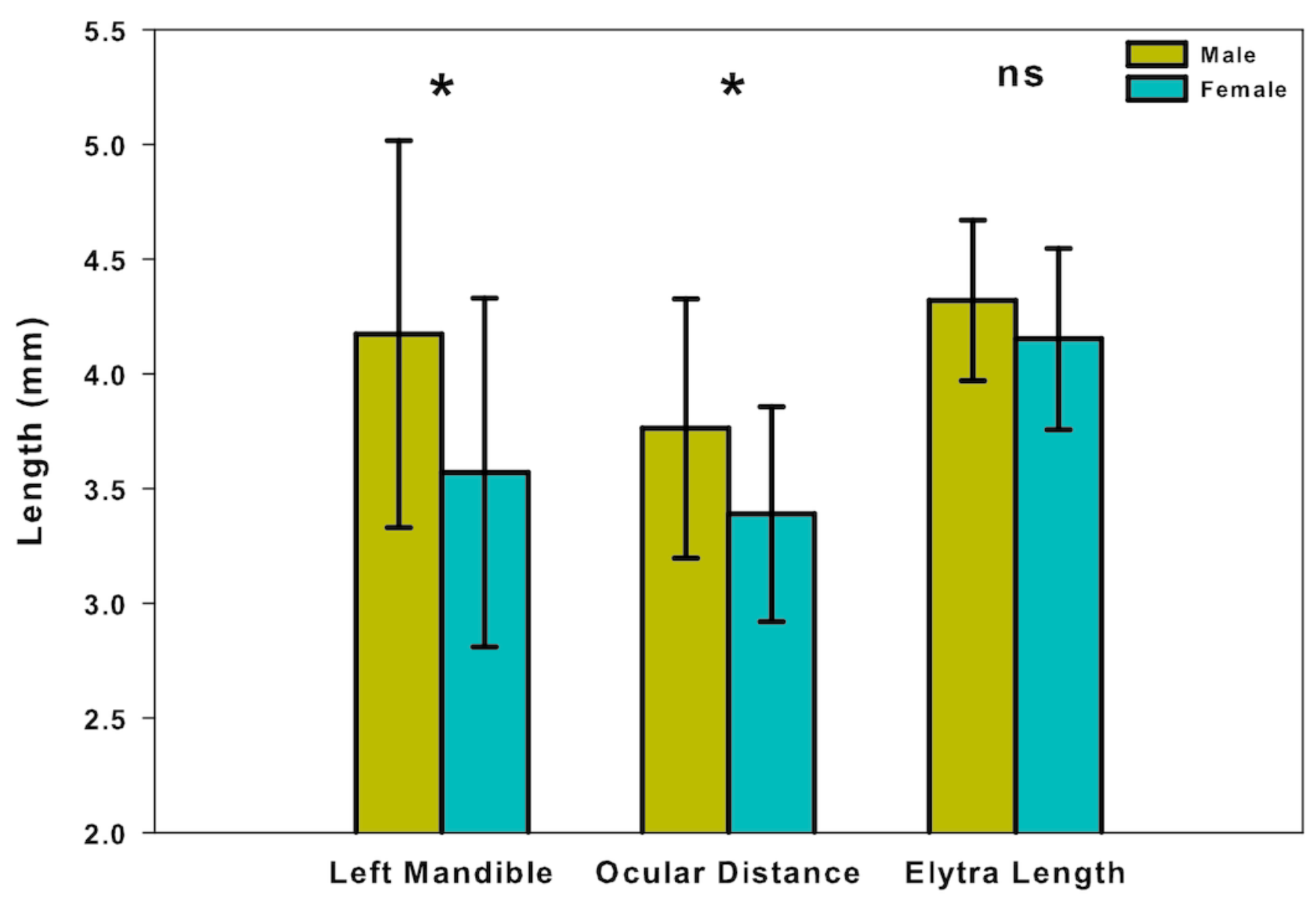


3

Scatter plot and linear regression between elytra length and left mandible

Fig 3 Scatter plot and linear regression between elytra length and left mandible for males and females. $\mathrm{N}=29$ males; $\mathrm{N}=22$ females.

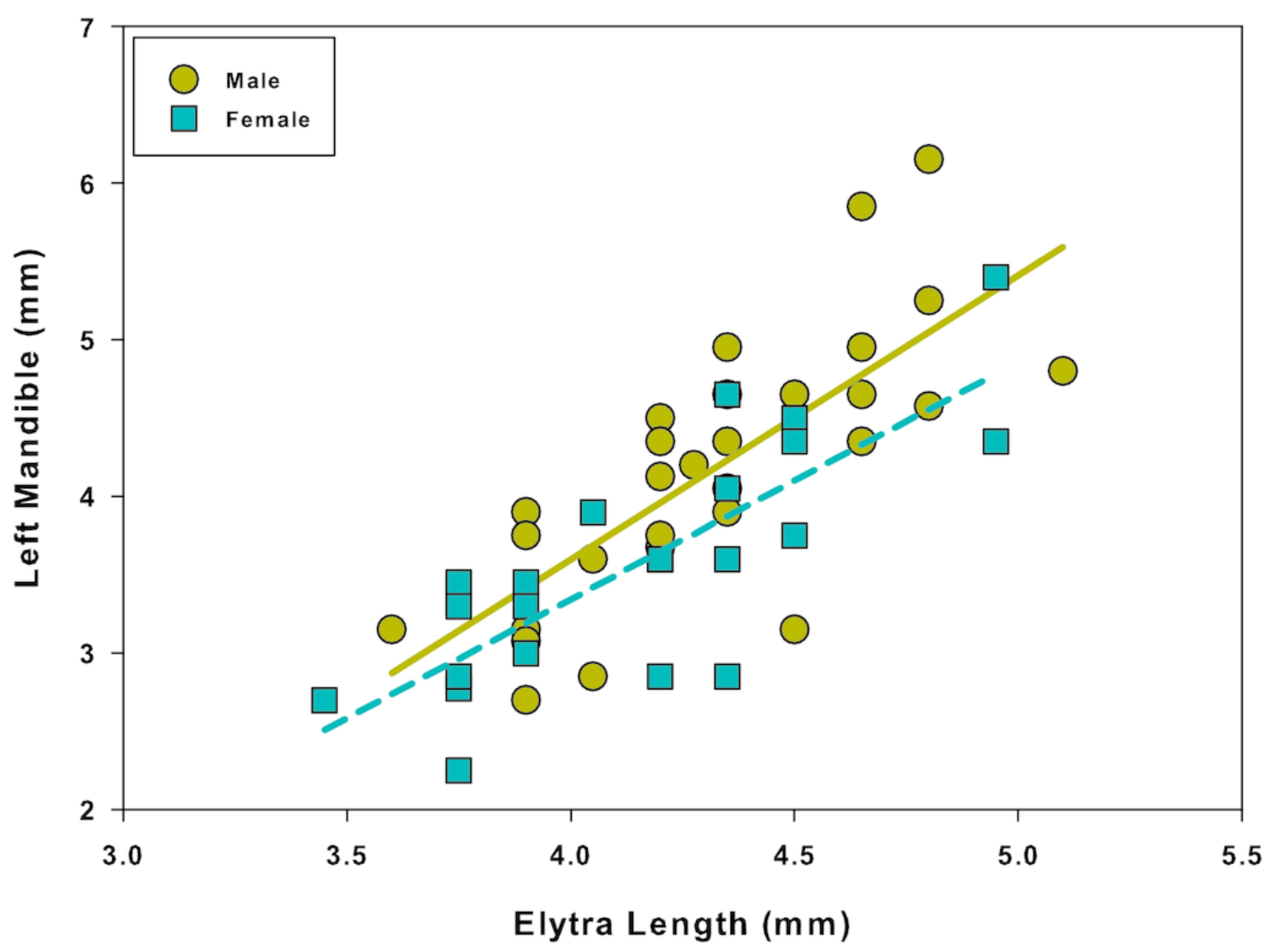


4

Scatter plot and linear regression between ocular distance and left mandible

Fig 4 Scatter plot and linear regression between ocular distance and left mandible for males and females. $\mathrm{N}=29$ males; $\mathrm{N}=22$ females.

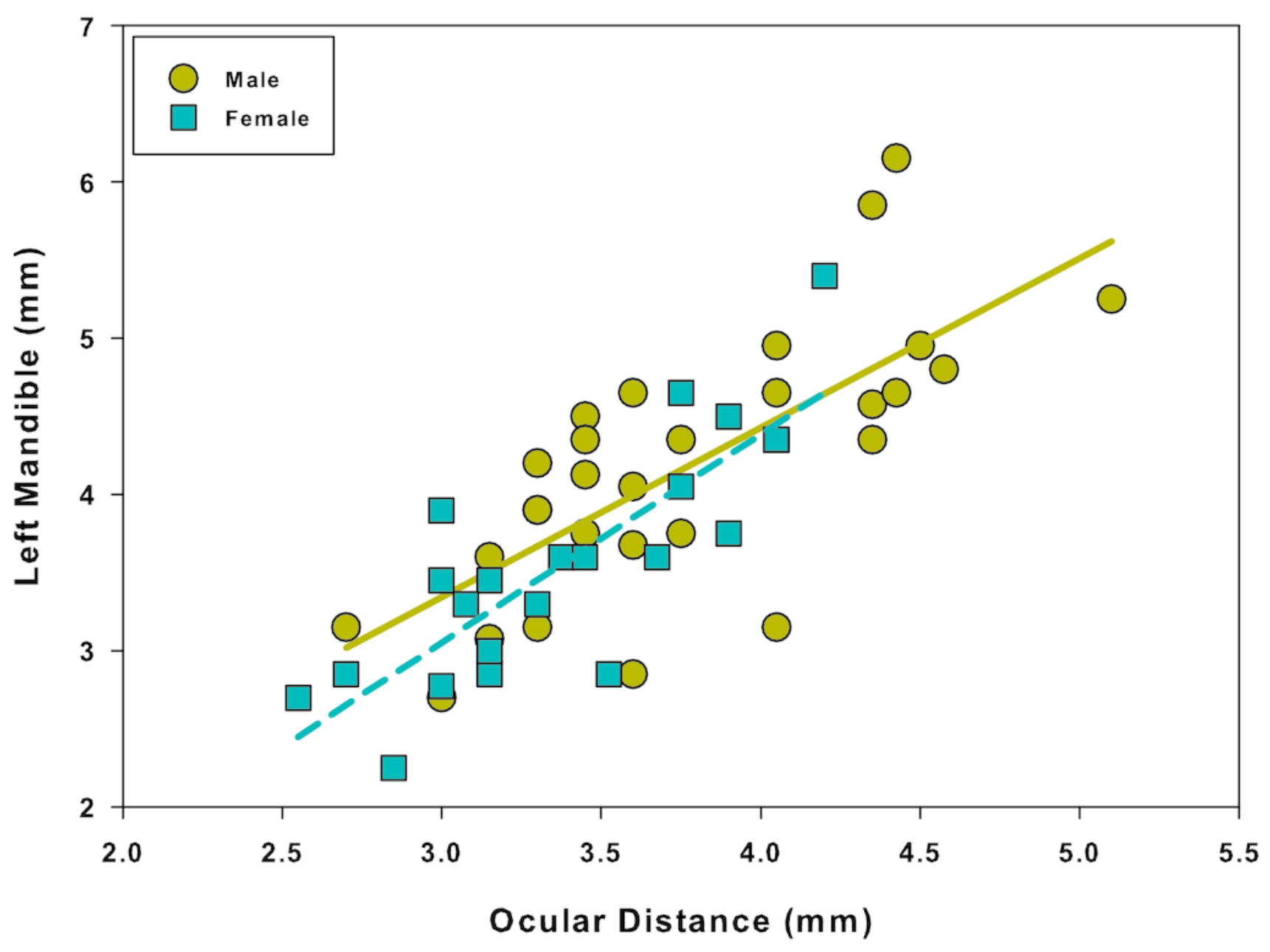




\section{5}

Scatter plot and linear regression between elytra length and ocular distance

Fig 5 Scatter plot and linear regression between elytra length and ocular distance for males and females. $\mathrm{N}=29$ males; $\mathrm{N}=22$ females.

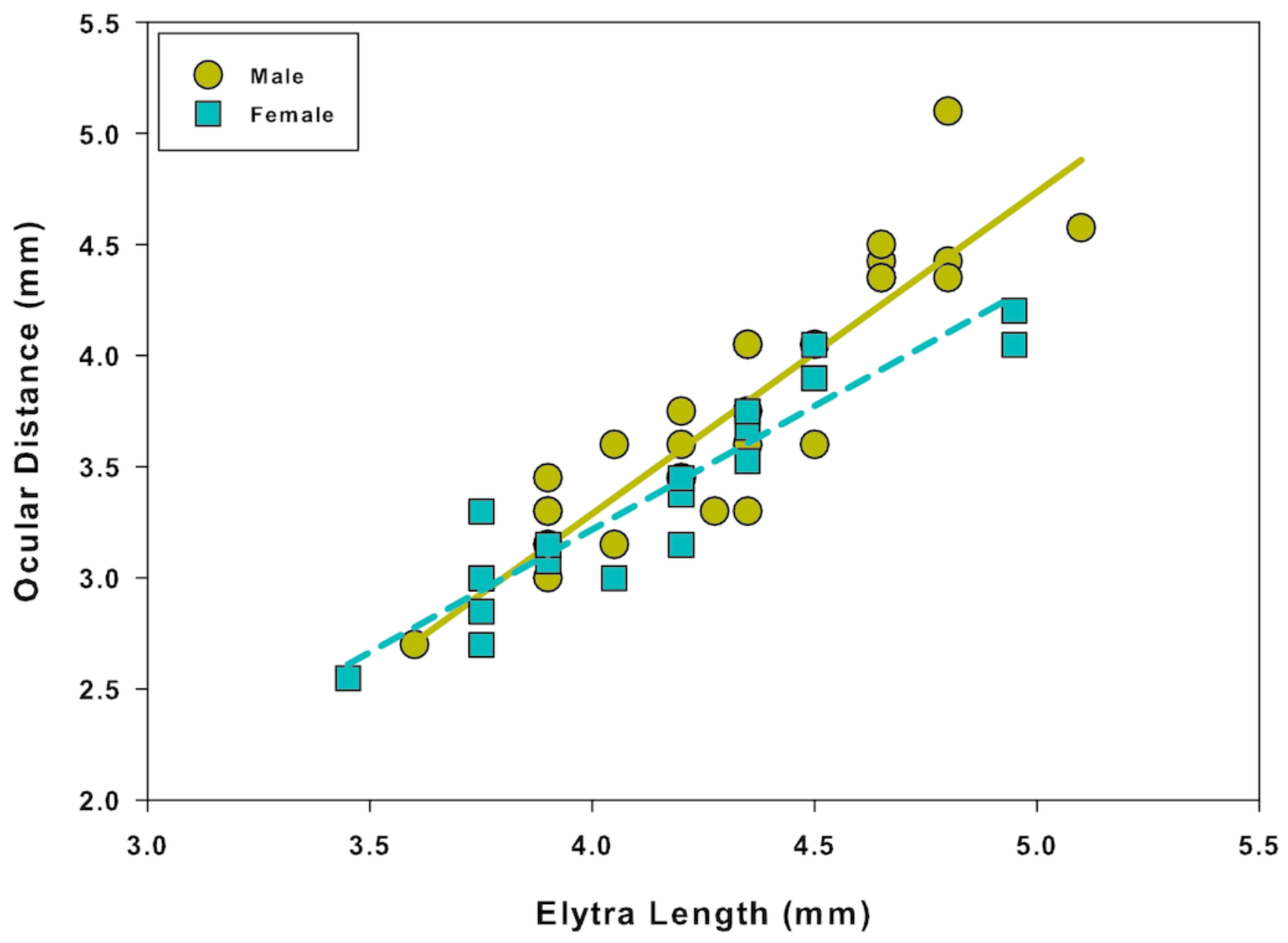




\section{Table $\mathbf{1}_{\text {(on next page) }}$}

Linear regression results for males and females for all three relationships.

Table 1. Linear regression results for males and females for all three relationships. $\mathrm{R} 2=$ correlation coefficient; $\mathrm{F}$ Statistic $=$ from the regression ANOVA; Intercept and Slope $=$ regression coefficients. Degrees of freedom: $27=$ males; $22=$ females. $n s=$ not significantly different from zero; $* p<0.05 ; * * p<0.01 ; * * * 00.001$. 


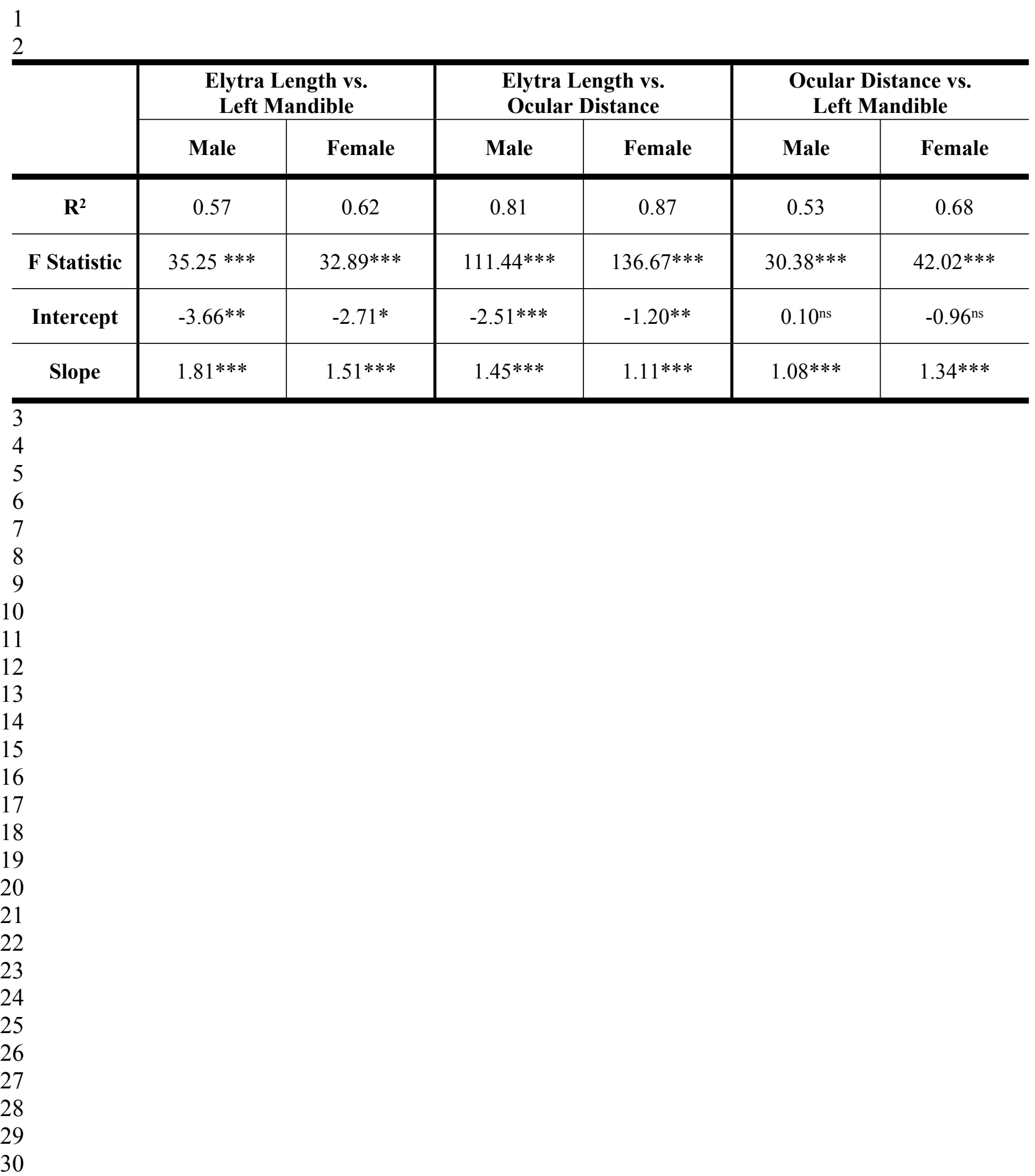


Table 2 (on next page)

Heterogeneity of slopes test results comparing linear regressions between male and females for each relationship.

Table 2. Heterogeneity of slopes test results comparing linear regressions between male and females for each relationship. Intercept and Slope $=$ regression coefficients. $* p<0.05$. 
1

2

\begin{tabular}{c|c|c|c|c|c|c}
\hline & \multicolumn{2}{|c|}{$\begin{array}{c}\text { Elytra Length vs. } \\
\text { Left Mandible }\end{array}$} & \multicolumn{2}{c|}{$\begin{array}{c}\text { Elytra Length vs. } \\
\text { Ocular Distance }\end{array}$} & \multicolumn{2}{c}{$\begin{array}{c}\text { Ocular Distance vs. } \\
\text { Left Mandible }\end{array}$} \\
\cline { 2 - 7 } & $\mathbf{F}_{1,47}$ & p-value & $\mathbf{F}_{1,47}$ & p-value & $\mathbf{F}_{1,47}$ & p-value \\
\hline Intercept & 0.30 & 0.587 & 3.22 & 0.079 & 0.94 & 0.336 \\
\hline Slope & 0.54 & 0.466 & 4.07 & $0.049^{*}$ & 0.68 & 0.413 \\
\hline
\end{tabular}

3

4

5

6

7

8

9

10

11

12

13

14

15

16

17

18

19

20

21

22

23

24

25

26

27

28

29

30

31

32

33

34

35 


\section{Table 3(on next page)}

Levels of significance for coefficient $\alpha_{2}$ in Model 1

Table 3. Levels of significance for coefficient $\alpha 2$ in Model 1. Degrees of freedom: Males $=2$, 26; Females $=2$, 19. Significance at $\alpha=0.05$. 


\begin{tabular}{c|c|c|c|c|c|c}
1 & \multicolumn{2}{c|}{} \\
\hline & \multicolumn{2}{|c|}{$\begin{array}{c}\text { Elytra Length vs. } \\
\text { Left Mandible }\end{array}$} & \multicolumn{2}{c}{$\begin{array}{c}\text { Elytra Length vs. } \\
\text { Ocular Distance }\end{array}$} & \multicolumn{2}{c}{$\begin{array}{c}\text { Ocular Distance vs. } \\
\text { Left Mandible }\end{array}$} \\
\cline { 2 - 7 } & Male & Female & Male & Female & Male & Female \\
\hline \multirow{2}{*}{$\boldsymbol{\alpha}_{2}$} & -1.27 & 1.24 & 0.22 & -0.87 & -0.20 & 1.64 \\
\hline $\mathbf{t}$ & -0.38 & 0.41 & 0.14 & -0.77 & -0.19 & 1.16 \\
\hline $\mathbf{p}$ & 0.706 & 0.687 & 0.891 & 0.449 & 0.852 & 0.262 \\
\hline 3
\end{tabular}

3 